\title{
EDUCAÇÃO DE JOVENS E ADULTOS: PERFIL DOS PROFESSORES E ALUNOS NUMA ESCOLA PÚBLICA
}

\author{
ADULT AND YOUTH EDUCATION: PROFILE OF TEACHERS AND STUDENTS IN A PUBLIC \\ SCHOOL
}

\section{EDUCACIÓN DE JOVENES Y ADULTOS: PERFIL DE DOCENTES Y ESTUDIANTES EN UNA ESCUELA PÚBLICA}

Recebido: 23/10/2014

Aprovado: 25/02/2015
César Henrique de Melo ${ }^{1}$

Álvaro da Silva Santos ${ }^{2}$

Niura Sueli de Almeida Martins ${ }^{3}$

Este é um estudo quantitativo e descritivo, que tem como objetivo caracterizar o perfil de docentes e alunos e identificar a presença de recursos didáticos e audiovisuais para a modalidade EJA; realizado com 12 docentes e 60 alunos numa escola pública de Uberaba-MG, através de entrevista a partir de questionário, no mês de Junho de 2014. Dentre os principais resultados destacam-se: $66,7 \%$ são do gênero feminino; $50 \%$ acima de 41 anos; 58,4\% tem graduação, 33,3\% tem especialização e 8,3\% mestrado; 50\% trabalham há mais de 21 anos; 66,7\% dos docentes trabalham na EJA de um a 10 anos; $100 \%$ referiu que o material didático e recursos audiovisuais são inadequados. No que se refere ao perfil dos alunos: sexo feminino, de 26 a 35 anos, casados, com filhos, trabalhadores com carteira assinada, com renda individual de 1 salário mínimo, morando em zona urbana e distante da EJA, sem apoio da empresa tanto para estudar, quanto para ações de capacitação. $O$ estudo mostrou a necessidade de se ampliar ações de capacitação aos professores e estímulos aos alunos, em especial na esfera de gestão pública da educação.

Descritores: Educação; Ensino fundamental e médio; Ensino.

This is a quantitative and descriptive study, that aims to characterize the profile of teachers and students and identify the presence of didactic and audiovisual resources for EJA mode; held with 12 teachers and 60 students in a public school of Uberaba-MG, Brazil, through interview from questionnaire in June 2014. Among the main results are: $66,7 \%$ are female gender; $50 \%$ over 41 years; $58,4 \%$ have a BA or BS, $33,3 \%$ have specialization and 8,3\% master's degree; $50 \%$ work as more than 21 years; $66,7 \%$ of teachers working in the EJA from one to 10 years; $100 \%$ stated that the teaching materials and audiovisual resources are inadequate. With regard to the students' profile: female, of the 2635 years, married, with children, workers officially registered, with individual income of 1 minimum wage, living in the urban area and distant from the EJA, without company's support both for study and for training actions. The study showed the need to expand training activities for teachers and students, in particular stimuli in the sphere of public administration education.

Descriptors: Education; Education primary and secondary; Teaching.

Este es un estudio cuantitativo y descriptivo, que tiene como objetivo caracterizar el perfil de profesores y alumnos e identificar la presencia de recursos didácticos y audiovisuales para el modo de EJA; hecho con 12 profesores y 60 alumnos en una escuela pública de Uberaba-MG, Brasil, a través de entrevista y cuestionario en junio de 2014. Entre los principales resultados destacanse: $66,7 \%$ son de sexo femenino; 50\% más de 41 años; 58,4\% hicieron La graduación, 33,3\% tienen especialización y 8,3\% mastria; 50\% trabajan más de 21 años; el 66,7\% de profesores que trabajan en la EJA de uno a 10 años; 100\% declaró que el material didáctico y recursos audiovisuales son inadecuados. En relación con el perfil del alumnado: mujer, de 26 de 35 años, casados, con hijos, trabajadores oficialmente registrados, con ingreso individual de 1 salario mínimo, viven en el área urbana y distante de la EJA, sin apoyo de la compañía para estudio y acciones formativas. El estudio demostró la necesidad de ampliar las actividades de formación para profesores y para alumnos, estímulos en el ámbito de la educación de la administración pública.

Descriptores: Educación; Educación primária y secundária; Enseñanza.

\footnotetext{
${ }^{1}$ Licenciatura Plena em Matemática. Especialista em Educação. Pós-graduando na modalidade MBA Gestão em Instituições Educacionais. E-mail: profchmelo@gmail.com

2 Enfermeiro. Especialista em Saúde Pública. Mestre em Administração em Saúde. Doutor em Ciências Sociais. Pós Doutorado em Serviço Social. Professor Adjunto III na Universidade Federal do Triângulo Mineiro.

3 Pedagoga. Mestre em Educação. Professora do Curso de Pedagogia da Faculdade Pitágoras e Coordenadora Pedagógica da Faculdade de Medicina da UNIVAÇO.
} 


\section{INTRODUÇÃO}

$\mathrm{A}$ Educação de Jovens e Adultos (EJA), de acordo com o artigo 37 da Lei de Diretrizes e Bases da Educação Nacional se apresenta como a "destinada àqueles que não tiveram acesso ou continuidade de estudos no ensino fundamental e médio ${ }^{1 "}$.

A EJA é uma modalidade educacional assegurada por lei para indivíduos que não conseguiram alcançar a educação regular por algum motivo, bem como, aqueles que não tiveram acesso ou a possibilidade de continuar os estudos no ensino fundamental e médio, época cronológica própria ${ }^{2}$.

A EJA pode ser uma possibilidade do resgate a um direito social que é a educação, e que dadas às características do seu público pode exigir caminhos diferentes da educação considerada regular.

Uma pesquisa sobre as legislações aponta que a escola na modalidade EJA prevê formar para cidadania e mercado de trabalho, mas se restringe a alfabetização e, na prática não se direciona ao público que deveria atender ${ }^{3}$.

Outro estudo qualitativo que analisou a percepção de alunos acerca do papel social da EJA demonstra que, o foco principal está na leitura, escrita e nos aprendizados básicos da matemática ${ }^{4}$.

Em linhas gerais Souza ${ }^{5}$ afirma que os alunos da EJA podem ser trabalhadores, aposentados, jovens empregados, aqueles em busca do $1^{\mathrm{o}}$ emprego, pessoas com necessidades educativas especiais.

Partindo deste norte, e da possível diversidade de grupos que podem procurar a EJA, ou seja, se fala de uma modalidade de ensino diferenciada, é de se esperar que o professor como facilitador de aprendizagens, deva ser preparado a esta vertente educativa.

Soares $^{6}$ relata que o professor para esta área idealmente deve ter formação em pedagogia com habilitação em Educação para Jovens e Adultos. Resguardada possíveis experiências exitosas, não é o que se vê na prática, o que pode não alcançar a proposta social inicialmente formatada, e com isto, ter se um ensino desconectado da realidade.
Desta forma, este estudo se justifica na medida em que pode oferecer elementos que possam fundamentar as políticas públicas na região pesquisada, já que não há pesquisas sobre EJA na cidade de Uberaba.

Com base no exposto, o presente estudo tem como objetivo caracterizar o perfil de docentes e alunos na modalidade EJA de uma escola pública de Uberaba-MG e identificar a presença de recursos didáticos e audiovisuais para esta tipologia de ensino, na visão dos professores.

\section{MÉTODO}

Este é um estudo de abordagem quantitativa e descritiva, realizada com professores e alunos da EJA de uma escola pública de Uberaba-MG.

A coleta de dados ocorreu em junho de 2014, através de um questionário para os professores com sete questões e para os alunos com 12 questões, após a autorização da direção da escola. Os docentes foram abordados na sala dos professores e os alunos por sua vez foram entrevistados em salas de aula (em número de quatro).

No caso dos professores, as variáveis estudadas foram gênero, idade, formação, tempo de magistério, tempo na EJA, presença de material didático e recursos audiovisuais. Já, os alunos, as variáveis eleitas foram gênero, idade, estado civil, presença de filhos, grau de escolaridade, ocupação, renda, e para os que trabalham se a empresa apoiam os estudos e se oferecem capacitação; bem como, se a sua residência é próxima à escola analisada. Foram pesquisadas quatro salas de aula, sendo duas de nível fundamental e duas de nível médio.

Em termos de análise, os dados foram tabulados e dispostos em figuras com a apresentação dos valores absolutos e percentuais, de modo que os dados de maior relevância foram discutidos com a literatura pertinente.

\section{RESULTADOS}

Esta pesquisa foi desenvolvida com 12 professores e 60 alunos de uma escola pública de Uberaba-Minas Gerais e que buscou delinear o perfil dos professores e alunos. 
Com relação ao perfil dos professores 15 são atuantes na EJA, mas apenas 12 professores foram entrevistados. Verificou-se que $66,7 \%$ são do gênero feminino; $50 \%$ têm acima de 41 anos, $41,7 \%$ estão entre 31 e 40 anos, e somente $8,3 \%$ tem entre 20 a 30 anos, conforme Quadro 1.

Quadro 1. Perfil de docentes da EJA e presença de recursos didáticos e audiovisuais de uma escola pública. Uberaba-MG, Junho de 2014.

\begin{tabular}{|l|r|r|}
\hline \multicolumn{1}{|c|}{ Variáveis } & $\mathbf{N}$ & \multicolumn{1}{|c|}{ \% } \\
\hline Gênero & & \\
Feminino & 8 & 66,7 \\
Masculino & 4 & 33,3 \\
\hline Idade & & \\
20 a 30 anos & 1 & 8,3 \\
31 a 40 anos & 5 & 41,7 \\
Acima de 41 anos & 6 & 50,0 \\
\hline Formação & & \\
Graduação & 7 & 58,4 \\
Especialização & 4 & 33,3 \\
Mestrado & 1 & 8,3 \\
\hline Tempo de atuação no Magistério & & \\
1 a 10 anos & & \\
11 a 20 anos & 2 & 16,7 \\
Acima de 21 anos & 4 & 33,3 \\
& 6 & 50,0 \\
\hline Tempo de atuação na EJA & & \\
1 a 10 anos & 8 & 66,7 \\
11 a 20 anos & 3 & 25,0 \\
Acima de 21 anos & 1 & 8,3 \\
\hline Material didático adequado à & & \\
realidade dos alunos? & & \\
Sim & 0 & 0,0 \\
Não & 12 & 100,0 \\
\hline Presença & & \\
audiovisuais para as aulas da EJA? & & \\
Sim & 0 & 0,0 \\
Não & 12 & 100,0 \\
\hline
\end{tabular}

Quanto à escolaridade, 58,4\% dos professores tem graduação, 33,3\% responderam ter especialização e 8,3\% disseram ter mestrado. Em relação ao tempo de atuação no magistério, 50\% trabalham como docentes há mais de 21 anos, $33,3 \%$ de 11 a 20 anos e 16,7\% estão trabalhando de um a 10 anos. Sobre a atuação na EJA, $66,7 \%$ dos docentes trabalham de um a 10 anos, $25 \%$ de 11 a 20 anos e somente $8,3 \%$ estão trabalhando acima de 21 anos. No que se refere ao uso do material didático e dos recursos audiovisuais nas aulas da EJA, os $100 \%$ dos professores entrevistados afirmaram que o material didático está incoerente com a realidade dos alunos e os recursos audiovisuais inexistentes (Quadro 1).

Sobre o perfil dos alunos, 72 alunos estavam inscritos, mas pesquisou-se 60 alunos, que estavam presentes como no Quadro 2.

Quadro 2. Perfil de alunos da EJA de uma escola pública. Uberaba-MG, junho de 2014.

\begin{tabular}{|l|r|r|}
\hline \multicolumn{1}{|c|}{ Variáveis } & N & \multicolumn{1}{|c|}{$\%$} \\
\hline Gênero & & \\
Feminino & 35 & 58,4 \\
Masculino & 25 & 41,6 \\
\hline Idade & & \\
15 a 25 anos & 12 & 20,0 \\
26 a 35 anos & 30 & 50,0 \\
Acima de 36 anos & 18 & 30,0 \\
\hline Estado civil & & \\
Solteiro & 6 & 10,0 \\
Casado & 45 & 75,0 \\
Separado & 9 & 15,0 \\
\hline Ter filhos & & \\
Sim & 48 & 80,0 \\
Não & 12 & 20,0 \\
\hline Nível de inserção na EJA & & \\
Ensino Fundamental & 23 & 38,3 \\
Ensino Médio & 37 & 61,7 \\
\hline Ocupação & & \\
Sim & 55 & 91,7 \\
Não & 5 & 8,3 \\
\hline Forma de ocupação & & \\
CLT & 39 & 70,9 \\
Autônomo & 16 & 29,1 \\
\hline Local de trabalho & & \\
Zona urbana & 50 & 90,9 \\
Zona rural & 5 & 9,1 \\
\hline Renda salarial & & \\
1 salário mínimo & 49 & 89,1 \\
2 a 3 salários mínimos & 6 & 10,9 \\
Acima de 3 salários mínimos & 0 & 0,0 \\
\hline Ajuda da empresa de trabalho & & \\
para os estudos & 5 & 9,1 \\
Sim & \\
Não & & 90,9 \\
\hline Presença de capacitação da \\
empresa & & \\
Sim & 5 & 9,1 \\
Não & & \\
\hline Proximidade da EJA & & \\
Sim & \\
Não & & \\
\hline
\end{tabular}

Dos pesquisados, $38,3 \%$ estavam matriculados na EJA nível fundamental e $61,7 \%$ EJA ensino médio. Observou-se que $58,4 \%$ dos alunos são do gênero feminino; $50 \%$ possuem de 26 a 35 anos, $30 \%$ acima de 
36 anos e $20 \%$ entre 15 a 25 anos; $75 \%$ dos alunos são casados, 15\% separados e 10\% são solteiros; $80 \%$ possuem filhos e $91,7 \%$ dos alunos são trabalhadores. Dos que trabalham, 70,9\% possuem carteira de trabalho assinada e $90,9 \%$ trabalham na zona urbana, com renda de até um salário mínimo $(89,1 \%)$; $65 \%$ não residem próximos às escolas que oferecem a EJA (Quadro 2).

\section{DISCUSSÃO}

Quanto ao perfil dos professores, no que se refere ao gênero observou predominância do sexo feminino $(66,7 \%)$. Em outros dois estudos verificou-se resultado idêntico a este $^{7,8}$. Na verdade esta tendência segue a do magistério em nível fundamental e médio ${ }^{9}$.

$\mathrm{Na}$ faixa etária verificou-se que 50\% têm acima de 41 anos, seguida de $41,7 \%$ que estão entre 31 a 40 anos. Estudos da cidade de Ponta Grossa e São Paulo apresentam trabalhos similares ${ }^{7,8}$. Possivelmente, fala-se aqui de pessoas com certa "maturidade" e que por isso se identifica com este trabalho.

Referente à formação do professor, obteve-se $58,4 \%$ de graduação, 33,3\% de especialização e $8,3 \%$ de mestrado. 0 ensino da EJA prevê estratégias didáticas adequadas a este grupo (que é diverso - adolescente, idoso, trabalhadores, entre outros), que pedem por conta disso um professor com preparo especial, para além da graduação, de no mínimo uma especialização que possa discutir temas correlacionados a esta tipologia educacional. Souza ${ }^{5}$ descreve que há deficiência na formação do professor na prática educacional levando o educador a reprodução da educação bancária tradicional.

Em relação ao tempo de atuação no magistério, $16,7 \%$ estão trabalhando de um a 10 anos, 33,3\% de 11 a 20 anos e 50\% acima de 21 anos. Sobre a atuação na EJA, 66,7\% dos docentes trabalham de um a 10 anos, $25 \%$ de 11 a 20 anos e somente 8,3\% estão trabalhando acima de 21 anos. Comparando os tempos de atuação no magistério e na EJA, é possível inferir que de algum modo a prática docente seja mais atraente na segunda modalidade porque todos os pesquisados adviram do magistério regular e poucos deles foram direto para a EJA. Um trabalho de pesquisa ${ }^{10}$ apresentado na $65^{\text {a }}$ Reunião Anual da SBPC (Sociedade Brasileira para o Progresso da Ciência) mostrou tempo inferior aos do estudo aqui em questão.

No que se refere aos recursos didáticos e audiovisuais $100,0 \%$ relatam serem inadequados ou inexistentes. Observa-se que, os recursos citados podem ser importantes, mas não garantem o êxito de uma aula para este grupo que tem características próprias. Possivelmente, técnicas grupais e mais participativas com os alunos podem dar maiores resultados. 0 Caderno de Orientações Didáticas para EJA Alfabetização ${ }^{11}$ aponta uma série de possibilidades didáticas, tais como leitura, uso da arte, dramatização entre outras, aspectos que fogem da presença única de recursos.

No caso dos alunos observou-se que $58,4 \%$ dos alunos são do gênero feminino; $20 \%$ entre 15 a 25 anos, $50 \%$ possuem de 26 a 35 anos, 30\% acima de 36 anos. Um estudo do Estado de Sergipe ${ }^{12}$ teve dados de perfil de gênero e faixa etária de frequentadores da EJA similar ao estudo aqui em questão. Por sua vez, dois outros estudos realizados em duas cidades do Piauí mostraram perfis de gênero diferentes $^{3}$. Por vezes, a opção entre estudar concorre com a jornada de trabalho, em que é preciso muita assertividade para decidir fazer os dois simultaneamente, situação que pode estar relacionado a qualquer nível de ensino, mas que aqui se fala de um contexto de "alguém que busca recuperar os estudos".

No que tange o estado civil $75 \%$ dos alunos são casados, $15 \%$ separados e $10 \%$ são solteiros. Um estudo ${ }^{13}$ identificou que $59,5 \%$ dos pesquisados eram casados e um pouco mais de $40 \%$ solteiros ou separados. A maior procura de casados para a EJA pode estar além da busca de ascensão social e sim a possibilidade de um emprego melhor, ou seja uma importante função social.

Dos pesquisados $91,7 \%$ dos alunos trabalham. Dos que trabalham 70,9\% possuem carteira de trabalho assinada e $90,9 \%$ trabalham na zona urbana, com renda de até um salário mínimo (89,1\%). Como coloca Ferrari ${ }^{14}$, o jovem que pertence ao mundo do trabalho, ou do desemprego, como é mais comum, incorpora-se ao curso 
da EJA objetivando atingir etapas de sua escolaridade para buscar melhores ofertas do mercado de trabalho por sua inserção no mundo letrado. Na pesquisa em questão os que trabalham percebem um salário muito baixo e tem filhos. A busca pela EJA pode ter proposta de ascensão a melhores oportunidades de emprego.

Como se verificou as empresas não são elementos motivadores para a busca da EJA, nem dando apoio, nem possibilidades de capacitação. Talvez dado ao baixo salário, a procura real se justifica na procura de uma maior educação no sentido de se galgar uma melhor ocupação no futuro.

A maioria dos alunos mora em área urbana, mas distante da escola. Um estudo também mostrou que a maioria dos alunos morava em área urbana ${ }^{15}$. A distância da escola pode ser um agente dificultador para a adesão e mesmo a manutenção do aluno na escola, além do seu desempenho. Por sua vez, pode-se inferir também que o número de EJAs possam não ser suficientes para a demanda.

\section{CONCLUSÃO}

0 perfil observado neste estudo aponta no caso dos professores: sexo feminino, idade entre acima de 41 anos, com graduação, acima de 21 anos de magistério regular e 1 a 10 anos EJA; o material didático e audiovisual é visto pelos mesmos como inadequados.

No que se refere ao perfil dos alunos: sexo feminino, de 26 a 35 anos, casados, com filhos, trabalhadores com carteira assinada, com renda individual de 1 salário mínimo, morando em zona urbana e distante da EJA, sem apoio da empresa tanto para estudar, quanto para ações de capacitação.

Os resultados deste estudo podem indicar a necessidade de maior capacitação para os professores, considerando que as necessidades didáticas do grupo EJA são diferentes do ensino regular, em especial no que refere as técnicas, o uso e adequação dos recursos, entre outros. Tal capacitação não tem que ser necessariamente só pósgraduação, mas também cursos de educação permanente, que podem pontualmente apoiar de forma mais rápida a sua prática.

Em relação aos alunos estímulos vindos das empresas devem ser ampliados, bem como, a busca da inserção cidadã do aluno, para além de um melhor emprego.

Este trabalho tem como limitações o fato de ter sido desenvolvido em uma única escola EJA e por isto sem a possibilidade de grandes generalizações, mas possivelmente reflete a realidade de outras localidades e merece ser mais amplamente investigada em outros estudos.

Fala-se aqui de uma ação conjunta da direção da escola em termos da participação da comunidade, e da intervenção política através do gestor educacional, quais sejam o secretário municipal e ou estadual de educação.

\section{REFERÊNCIAS}

1. Ministério da Educação (Br). Lei de Diretrizes e Bases da Educação. 9.394/96. Brasília: Ministério da Educação, 1996.

2. Sousa KC, Cunha NS. Perfil dos alunos de educação de jovens e adultos de Teresina. 2010. Trabalho de Conclusão de Curso de Pedagogia - Universidade Federal do Piauí. Disponível:

http://www.ufpi.br/subsiteFiles/ppged/arqui vos/files/VI.encontro.2010/GT.19/GT_19_03_ 2010.pdf Acesso em: 15 nov. 2014.

3. Silva FM, Barbosa MA, Uytdenbroek X. A função social da escola na educação de jovens e adultos. Escola: pra quê te querem. 2008. Trabalho de Conclusão de Curso de Pedagogia - Centro de Educação da Universidade Federal de Pernambuco. Disponível em: https://www.ufpe.br/ce/images/Graduacao_p edagogia/pdf/2008.1/a\%20funo $\% 20$ social $\% 2$ 0da $\% 20$ escola $\% 20$ na $\% 20$ educao $\% 20$ de $\% 20$ j ovens $\% 20 \mathrm{e} \% 20$ adultosvier\%20uytdenbroek. pdf

Acesso em: 16 nov. 2014.

4. Silva EJL. Os enunciados da função social da escola nos discursos de educandos de jovens e adultos. Educação: teoria e prática 2013; 23(42):54-71. Disponível em: http://educa.fcc.org.br/pdf/eduteo/v23n42/v2 3n42a05.pdf Acesso em 19 nov.2014.

5. Souza MA. Educação de Jovens e Adultos. 2 ed. Curitiba 2011: Xibpex dialógica. p.198 


\section{Melo CH, Santos AS, Martins NSA}

6. Soares LJG. 0 educador de jovens e adultos e sua formação. Educação em Revista 2008; 47:83-100. Disponível em: http://www.scielo.br/scielo.php?script=sci_ar ttext\&pid=S0102-

46982008000100005\#back4 Acesso: 17 nov. 2014.

7. Scortgagna PA, Oliveira RCS. Trabalho docente na EJA na cidade de Ponta Grossa: reflexões sobre políticas públicas. 2014. Disponível em: http://www.anpae.org.br/simposio26/1comu nicacoes/PaolaScortegagnaeRitaOliveira-

ComunicacaoOral-int.pdf Acesso em: 18 nov. 2014

8. Bedoya MJA, Teixeira RRP. Perfil dos professores da educação de jovens e adultos. ATHENA - Revista Científica de Educação 2008; 10(10):63-75 Disponível em: <http://faculdadeexpoente.edu.br/upload/not iciasarquivos/1243985854.pdf>. Acesso em: 19 nov. 2014.

9. Instituto Nacional de Estudos e Pesquisas Educacionais Anísio Teixeira (INEP). Pesquisa Internacional sobre Ensino e Aprendizagem (TALIS). Organização para a Cooperação e Desenvolvimento Econômico (OCDE). Brasília: INEP, 2014. Disponível em: http://portal.inep.gov.br/visualizar//asset_publisher/6AhJ/content/pesquisainternacional-revela-perfil-de-professor-ediretor

10. Oliveira RT, Bruno KRP, Borges DSP, Santos IC, Melo SJM. O olhar dos professores que atuam na EJA sobre a formação continuada oferecida pela Secretaria de Educação do Estado do Amapá. 65a 2013. Disponível em:< http://www.sbpcnet.org.br/livro/65ra/resum os/resumos/2189.htm>. Acesso em: 17 nov. 2014

11. Secretaria Municipal de Educação (Cidade de São Paulo). Caderno de Orientações Didáticas Para EJA - Alfabetização. Etapas

\section{Ensino de Jovens e Adultos}

Alfabetização e Básica, 2010. 142 p. Disponível:<

http://portalsme.prefeitura.sp.gov.br/Projetos /BibliPed/Documentos/publicacoes/orienta_a lf_portal.pdf>. Acesso em: 16 nov. 2014

12. Fernandes PD, Oliveira KKS. Um olhar sobre a formação do docente que leciona na educação de jovens e adultos (EJA) 2013. p. 111. Disponível em: <http://midia.unit.br/enfope/2013/GT1/UM OLHAR_FORMACAO_DOCENTE_LECIONA_EDU CACAO_JOVENS_ADULTOS.pdf $>$. Acesso em: 20 nov. 2014.

13. Bastiani DM. Perfil e desafios dos alunos da educação de jovens e adultos do Município de Santa Helena - PR. 2011. Monografia de Especialização - Universidade Tecnológica Federal do Paraná. 44 p. Acessível em:< http://repositorio.roca.utfpr.edu.br/jspui/bits tream/1/1646/1/MD_PROEJA_2012_IV_05.pdf $>$. Acesso em 14 nov. 2014

14. Ferrari SC. O aluno de EJA: jovem ou adolescente? 2011. Disponível em: http://www.cereja.org.br/pdf/revista_v/Revis ta_ShirleyCostaFerra.pdf. Acesso em: 14 nov. 2014

15. Ajala MC. Aluno EJA: motivos de abandono e retorno escolar na modalidade EJA e expectativas pós EJA em Santa Helena - PR. Monografia de Especialização - Universidade Tecnológica Federal do Paraná. 44 p. 2011. Disponível em: <http://repositorio.roca.utfpr.edu.br/jspui/bit stream/1/1647/1/MD_PROEJA_2012_IV_16.p df>. Acesso em: 20 nov. 2014.

\section{CONTRIBUIÇÕES}

César Henrique de Melo foi responsável pela coleta de dados, desenho do estudo e redação final do artigo. Álvaro da Silva Santos fez análise crítica do estudo e teve inserção na redação do artigo. Niura Sueli de Almeida Martins orientou o estudo e participou da redação final do artigo. 